\title{
IEDITORIAL
}

\section{The POL-OHCA registry: good news for patients and scientists}

Fernando Rosell Ortiz

La Rioja Emergency Medical Service 061, Hospital San Pedro, Logroño, Spain

RELATED ARTICLE by Nadolny et al, see p. 404
Correspondence to: Fernando Rosell Ortiz, MD, PhD, La Rioja Emergency Medical Service 061, Hospital San Pedro, C/ Piqueras 92, 26006 Logroño, Spain, phone: +34941298325 , email: fernandorosell@gmail.com Received: May 3, 2020. Accepted: May 4, 2020. Published online: May 25, 2020. Kardiol Pol. 2020; 78 (5): 377-378 doi:10.33963/KP.15379 Copyright by the Author(s), 2020
Out-of-hospital cardiac arrest (OHCA) is a major public health problem. The European Parliament itself pointed this out in a declaration in June 2012. In that document, the institution called for measures to make effective resuscitation available to all European citizens, such as launching programs to train people in basic life support, improving access to prompt defibrillation, the adjustment of legislation to facilitate resuscitation and defibrillation by nonmedical persons, and "systematic data collection for feedback and quality management in every program."1

Not only political but also key scientific institutions which are involved in research and possess knowledge of cardiac arrest have recognized the need to establish registries as the first step to improve survival in patients with OHCA. ${ }^{2-4}$ Only the area which is known, analyzed, and facilitates the evaluation of possible interventions over time can be improved. Case registries are key tools for the continuous improvement of care quality.

In this issue of Kardiologia Polska (Kardiol Pol, Polish Heart Journal), Nadolny et $\mathrm{al}^{5}$ presented excellent news regarding OHCA, which is of importance to both patients and scientists. Before this publication, recent data on OHCA in Poland came from 2 initiatives of the EuReCa (European Registry of Cardiac Arrest) project: the 1-month EuReCa ONE and the 3-month EuReCa TWO studies. ${ }^{6,7}$ However, they provided only partial data based on a relatively small proportion of the country's population.

With 1-year data from all over the country and more than 26700 cases included, the step taken by the Polish OHCA registry is of paramount importance. It contributes to a relevant flow of information and represents a starting point for further detailed analysis. Besides, the results shown by Nadolny et $\mathrm{al}^{5}$ are also encouraging.
With a high number of attempts at resuscitation per 100000 inhabitants, just over a third of the patients treated could reach the hospital, with a small percentage of cases of ongoing resuscitation, hardly $1 \%$. Moreover, these results did not show significant variability among the provinces. Apart from that, considering the percentage of initial defibrillable rhythms, which is slightly above $20 \%$ and similar to the European average, ${ }^{6,7}$ the general impression of the prehospital care for patients with OHCA in Poland is fairly positive.

Despite these advantages, as the authors highlighted in the comment on the limitations of the registry, lack of some data makes in-depth analysis difficult. In this aspect, there are $2 \mathrm{im}$ portant issues that require effort on the part of those responsible for the registry.

The first task is to check whether the inclusion criteria of the registry work properly. The inclusion criteria, that is, the status of a patient treated with defibrillation and/or at least 1 dose of epinephrine, $1 \mathrm{mg}$, by the emergency medical service ambulance staff, may exclude patients from the registry in whom resuscitation would present problems with meeting either of the 2 criteria. If these criteria are not checked with diagnoses established by emergency teams, errors can occur, particularly in the case of inclusion based on epinephrine use. This is an essential issue that affects all OHCA registries. It is well known that the inclusion of all consecutive patients requires significant and constant effort over time. Even the registries which have been operated for many years and significantly contributed to scientific endeavors deal with this difficulty and disparate results are noted while performing specific quality assessment. In general, the nonincluded cases tend to show worse outcomes. ${ }^{8}$ 
Second, it would be highly desirable to match the variables and definitions as stipulated in the Utstein form. This is necessary to analyze, compare, and understand not only the data obtained but also trends and consequences of possible interventions and strategies adopted in the treatment of OHCA at different levels of healthcare.

This should apply at least to the variables considered to be the core of the Utstein form. First, the variables related to critical actions prior to the arrival of an emergency team at the scene need to be dealt with. These actions have a very important influence on outcomes and have demonstrated their effectiveness over time, particularly when national strategies have been adopted to spread their application. ${ }^{9}$ Of note, not all links have the same impact on patient prognosis. ${ }^{10}$ The recognition of priorities in the dispatch center is a very intriguing issue related to this initial phase of care. The distinction between priorities can offer the possibility to detect a potential OHCA situation, which is more important than the different response times, 60 seconds for $C-1$ interventions versus 120 seconds for $C-2$. Thus, it would be useful to categorize the $C-2$ priorities by processes, with questionnaires designed to identify breathing difficulty, the main determinant of possible errors in the detection of $\mathrm{OHCA} .{ }^{11}$ It is of paramount importance to identify agonal breathing or gasping during the call, which often precedes cardiac arrest by a very short time. There is strong evidence that prompt initiation of resuscitation during the gasping phase is associated with increased survival. ${ }^{12}$ In the chain of survival, dispatch centers should play a proactive role in identifying and achieving the immediate initiation of resuscitation by witnesses.

Second, it would be valuable to determine patients' final outcomes in terms of survival at hospital discharge or at 1 month. Ideally, including patients' neurologic status. It should be emphasized that without survival data we can only evaluate part of the process, not the final health-centered outcomes. Without such hospital data, the last link in the chain of survival, which is closely associated with the final outcome, is therefore omitted in the analysis. For instance, both percutaneous coronary intervention in OHCA caused by ST-segment elevation myocardial infarction and hypothermia have demonstrated a profound influence on survival with good neurologic status..$^{13,14}$ Moreover, there are conflicting data on the impact of the characteristics of the destination hospital on patient survival. ${ }^{15,16}$ This is a crucial factor in understanding possible variability among regions, which can even help to select the most suitable hospital in particular areas where more than 1 center can be chosen.

In spite of these limitations, the authors of the POL-OHCA registry have come up with their own, very interesting and even enviable, conditions. Establishing a common emergency research system for the whole country, the Command Support System, and cooperation between institutions, the Polish Ministry of Health and the National Center for Monitoring Emergency Medicine, are 2 fundamental conditions for the feasibility and continuity of a difficult project, an OHCA registry that provides data on a population of 38 million inhabitants. No doubt, excellent news.

\section{ARTICLE INFORMATION}

DISCLAIMER The opinions expressed by the author are not necessarily those of the journal editors, Polish Cardiac Society, or publisher.

NOTE FRO is a member of the Steering Committee of the EuReCa project.

CONFLICT OF INTEREST None declared.

OPEN ACCESS This is an Open Access article distributed under the terms of the Creative Commons Attribution-NonCommercial-NoDerivatives 4.0 International License (CC BY-NC-ND 4.0), allowing third parties to download articles and share them with others, provided the original work is properly cited, not changed in any way, distributed under the same license, and used for noncommercial purposes only. For commercial use, please contact the journal office at kardiologiapolska@ptkardio.pl.

HOW TO CITE Rosell Ortiz F. The POL-OHCA registry: good news for patients and scientists. Kardiol Pol. 2020; 78: 377-378. doi:10.33963/KP.15379

\section{REFERENCES}

1 Declaration of the European Parliament of 14 June 2012 on establishing a European cardiac arrest awareness week. European Parliament website. https:// www.europarl.europa.eu/sides/getDoc.do?pubRef=-//EP//TEXT+TA+P7-TA-20120266+0+DOC+XML+V0//EN. Accessed April 21, 2020

2 Resuscitation Academy. 10 Steps for Improving Survival from Sudden Cardiac Arrest. 2nd ed. Resuscitation Academy Foundation; 2020. http://www.resuscitationacademy.org/ebook/. Accessed April 21, 2020.

3 Global Resuscitation Alliance. Improving survival from out-of-hospital cardiac arrest. Acting on the call: 2018 update from the global resuscitation alliance including 27 case reports. https://www.globalresuscitationalliance.org/wp-content/ pdf/acting_on_the_call. Published April 2018. Accessed April 21, 2020.

4 Graham R, McCoy MA, Schultz AM, eds. Strategies to Improve Cardiac Arrest Survival: a Time to Act. The National Academies Press; 2015. https://www.ncbi.nlm. nih.gov/books/NBK305685/. Accessed April 21, 2020.

5 Nadolny K, Zyśko D, Obremska M, et al. Analysis of out-of-hospital cardiac arrest in Poland in a 1-year period: data from the POL-OHCA registry. Kardiol Pol. 2020; 78: 404-411.

6 Gräsner JT, Lefering R, Koster RW, et al. EuReCa ONE-27 Nations, ONE Europe, ONE Registry. a prospective one month analysis of out-of-hospital cardiac arrest outcomes in 27 countries in Europe. Resuscitation. 2016; 105: 188-195.

7 Gräsner JT, Wnent J, Herlitz J, et al. Survival after out-of-hospital cardiac arrest in Europe - Results of the EuReCa TW0 study. Resuscitation. 2020; 148: 218-226.

8 Strömsöe A, Svensson L, Axelsson ÅB, et al. Validity of reported data in the Swedish Cardiac Arrest Register in selected parts in Sweden. Resuscitation. 2013; 84: 952-956.

9 Wissenberg M, Lippert FK, Folke F, et al. Association of national initiatives to improve cardiac arrest management with rates of bystander intervention and patient survival after out-of-hospital cardiac arrest. JAMA. 2013; 310: 1377-1384.

10 Deakin CD. The chain of survival: not all links are equal. Resuscitation. 2018; 126: 80-82.

11 Bång A, Herlitz J, Martinell S. Interaction between emergency medical dispatcher and caller in suspected out-of-hospital cardiac arrest calls with focus on agonal breathing: a review of 100 tape recordings of true cardiac arrest cases. Resuscitation. 2003; 56: 25-34.

12 Bobrow B], Zuercher M, Ewy GA, et al. Gasping during cardiac arrest in humans is frequent and associated with improved survival. Circulation. 2008; 118: 2550-2554.

13 Khera R, CarlLee S, Blevins A, et al. Early coronary angiography and survival after out-of-hospital cardiac arrest: a systematic review and meta-analysis. Open Heart. 2018; 5: e000809.

14 Schenone AL, Cohen A, Patarroyo G, et al. Therapeutic hypothermia after cardiac arrest: a systematic review/meta-analysis exploring the impact of expanded criteria and targeted temperature. Resuscitation. 2016; 108: 102-110.

15 Worthington H, Pickett W, Morrison LJ, et al. The impact of hospital experience with out-of-hospital cardiac arrest patients on post cardiac arrest care. Resuscitation. 2017; 110: 169-175.

16 Koyama S, Gibo K, Yamaguchi Y, Okubo M. Variation in survival after out-of-hospital cardiac arrest between receiving hospitals in Japan: an observational study. BMJ Open. 2019; 9: e033919. 